\title{
Irradiation response of delta ferrite in as-cast and thermally aged cast stainless steel
}

\author{
Zhangbo $\mathrm{Li}^{1}$, Wei-Yang $\mathrm{Lo}^{1}$, Yiren Chen ${ }^{2}$, Janne Pakarinen ${ }^{3}$, Yaqiao $\mathrm{Wu}^{4,5}$, Todd Allen ${ }^{6,7}$ and \\ Yong Yang ${ }^{1 *}$
}

1. Department of Materials Science and Engineering, Nuclear Engineering Program, University of Florida, Gainesville, FL 32611, USA

2. Nuclear Engineering Division, Argonne National Laboratory, Lemont, IL 60439, USA

3. Belgian Nuclear Research Center (SCK•CEN), Boeretang 200, B-2400 Mol, Belgium

4. Department of Materials Science and Engineering, Boise State University, Boise, ID 83715, USA

5. Center for Advanced Energy Studies, Idaho Falls, ID 83401, USA

6. Engineering Physics Department, University of Wisconsin, Madison, WI 53706, USA

7. Idaho National Laboratory, Idaho Falls, ID 83415, USA

\begin{abstract}
To enable the life extension of Light Water Reactors (LWRs) beyond 60 years, it is critical to gain adequate knowledge for making conclusive predictions to assure the integrity of duplex stainless steel reactor components, e.g. primary pressure boundary and reactor vessel internal. Microstructural changes in the ferrite of thermally aged, neutron irradiated and thermally aged plus neutron irradiated cast austenitic stainless steels (CASS) were investigated using atom probe tomography. The thermal aging was performed at $400^{\circ} \mathrm{C}$ for 10,000 hours and the irradiation was conducted in the Halden reactor at $\sim 315^{\circ} \mathrm{C}$ to 0.08 dpa $\left(5.6 \times 10^{19} \mathrm{n} / \mathrm{cm}^{2}, \mathrm{E}>1 \mathrm{MeV}\right)$. Low dose neutron irradiation at a dose rate of $2 \times 10^{-9} \mathrm{dpa} / \mathrm{s}$ was found to induce spinodal decomposition in the ferrite of as-cast microstructure, and further to enhance the spinodal decomposition in the thermally aged cast alloys. Regarding the G-phase precipitates, the neutron irradiation
\end{abstract}

\footnotetext{
${ }^{*}$ Corresponding author. Tel.: + 352846 3791; fax: + 352392 7129. E-mail addresses: yongyang@ufl.edu (Y.Yang).
} 
dramatically increases the precipitate size, and alters the composition of the precipitates with increased ,Mn, Ni, Si and Mo and reduced Fe and Cr contents. The results have shown that low dose neutron irradiation can further accelerate the degradation of ferrite in a duplex stainless steel at the LWR relevant condition.

\section{Introduction}

To extend the service lifetime of Light Water Reactors (LWRs) beyond 60 years, the integrity of reactor components and the performance of structural materials must be evaluated adequately. The accurate assessment and prediction of materials performance under anticipated operation conditions are of particular importance for ensuring the safe operation of nuclear power plants over their extended lifetime. Both the cast austenitic stainless steels (CASS) and welds of austenitic stainless steel in LWRs consist of a duplex phase structure that contains austenite and delta ferrite phases. While the CASS alloys are mainly used in LWRs primary pressure boundary components, such as, coolant pipes, elbows, valves bodies, and pump casings, the welds for austenitic stainless steels can be found throughout the primary pressure boundary and reactor vessel internal components. The common cast stainless steels in service include the CF-3 and CF-8 series of alloys with a ferrite content up to 30\%, and for the welds, e.g. 308 type, ferrite contents are limited to less than 20\%. The ferrite phase improves the tensile strength, castability, weldability and stress-corrosion cracking resistance. In general, duplex stainless steel components perform properly with relatively few degradation modes, however, it has been long known that potentially significant embrittlement can be present due to the precipitation of fine second phases and spinodal decomposition of ferrite phase upon extended long-term thermal aging at temperatures of $280-350^{\circ} \mathrm{C}[1,2]$.

Earlier studies on CASS by Chung and Chopra [3-5] concluded that the spinodal decomposition into Fe-rich $\alpha$ and Cr-rich $\alpha$ ' phases and nucleation and growth of $\mathrm{G}, \gamma_{2}$, and $\mathrm{M}_{23} \mathrm{C}_{6}$ carbide phases are the metallurgical processes contributing to the thermal-aging embrittlement of the ferrite phase. However, the primary embrittlement mechanism of aged CASS is the formation of Cr-rich $\alpha$ ' phase. The effects of thermal aging on mechanical properties include increases in tensile strength and hardness but decreases in ductility, fracture toughness and impact strength [6-8]. Austenitic stainless steel welds share a very similar embrittlement mechanism with CASS 
upon thermal aging [9-12]. As an example, studies on thermally aged, unirradiated 316 SS welds consistently showed that the spinodal decomposition is the primary aging mechanism of the duplex weld materials [13]. Long-term thermal aging resulted in changes in fracture toughness that initially increased, then decreased with increasing aging time.

In addition to thermal aging, it is well known that the irradiation-enhanced diffusion can induce or accelerate phase transformations and hardening in stainless steels. Although CASS materials are not typically subjected to high neutron fluence, some CASS components, such as core support columns and mixing devices, may reach fluence level on the order of $10^{20} \mathrm{n} / \mathrm{cm}^{2}(E>1$ $\mathrm{MeV}$ ). Austenitic stainless steel welds used as PWR internals (e.g. core barrel welds and flux thimble tube plugs) can, as noted in the ERPI technical reports [14, 15], be located in the high fluence regions with anticipated neutron fluence on the order of $10^{22} \mathrm{n} / \mathrm{cm}^{2}$. Although the thermal aging induced embrittlement mechanism in duplex stainless steels has been well studied and understood, the irradiation effects and the potential combined effects of thermal aging and neutron embrittlement are yet to be fully investigated. There have been several studies on the weld overlay cladding of reactor pressure vessels [16], F-32Cr\% model alloy [17] and ionirradiated CF8M duplex stainless steel [18], but the results are inconclusive and even contradictory. Therefore, more systematic studies are needed.

In this paper, microstructural comparisons of ferrite in a cast stainless steel CF-3 are made among the conditions of as-cast, thermally aged, neutron irradiated, and neutron irradiated after thermal aging. It is aimed to elucidate whether the irradiation will further exaggerate the thermal aging degradation.

\section{Experiments}

The chemical composition of cast stainless steel CF-3 used in this study is listed in Table 1. The material contains $24 \%$ volumetric fraction of ferrite. Some of the as-cast samples were aged at $400^{\circ} \mathrm{C}$ for 10,000 hours prior irradiation, and the neutron irradiation on the un-aged and aged samples was conducted in the Halden reactor at $315^{\circ} \mathrm{C}$ to $0.08 \mathrm{dpa}\left(5.6 \times 10^{19} \mathrm{n} / \mathrm{cm}^{2}, \mathrm{E}>1 \mathrm{MeV}\right.$ with a dose rate of $2.8 \times 10^{-9} \mathrm{dpa} / \mathrm{s}$ ). The optical image of Fig. 1 shows a general grain and phase structure of the as-cast stainless steel. No obvious change of this structure was identified after thermal aging or neutron irradiation. 
In this paper, the characterizations were solely focused on the spinodal decomposition and nanosized G-phase precipitation in ferrite using atom probe tomography (APT) technique. The APT probe specimens were fabricated using a focused ion beam (FEI 3D Quanta FEG FIB), and the samples were finished using ion beam imaging for 1 minute at beam energy of $2 \mathrm{kV}$ and current of 27pA to ensure a minimal Ga implantation and radiation damage from ion beam. For each condition, a minimum of nine tips was fabricated while averagely four specimens tips were fractured before a good size of dataset was achieved. The 3-D reconstruction and analysis were performed using the Interactive VisuAlization Software (IVAS 3.6.8). The 3D reconstructions were conducted by following the standard procedure of the Recon Wizard in the software, and SEM tip images were used for defining tip profiles. The evaporation field value was 33.0V/nm and $\mathrm{k}$ factor of 3.30 was used. Both the FIB and APT equipment used for this study are located at the Microscopy and Characterization Suite (MaCS), Center for Advanced Energy Studies (CAES) in Idaho Falls, ID.

\section{Results and discussion}

Overall, the delta ferrites in this cast stainless steel show a good chemical homogeneity. Table 2 lists the APT measured chemical compositions of the ferrites at four different conditions, and the standard deviations (sd) are calculated over all the measured specimens. For the major alloying elements, Fe, Cr, Ni, Mn and Si, the concentrations show a great consistence, and even for the elements of $\mathrm{P}, \mathrm{S}$ and $\mathrm{C}$ with very low concentrations, the measured values vary insignificantly by considering a relative large measurement error for the minor alloying elements.

\subsection{Spinodal decomposition in ferrite}

Figure 2 shows a direct comparison of $\mathrm{Cr}$ atom maps in the as-cast, aged, irradiated, and aged and irradiated ferrite phases. The atomic maps were constructed from a slice of $5 \mathrm{~nm}$ in thickness at the Y-middle plane of each APT tip. The atom maps clearly illustrate that both thermal aging and irradiation can individually induce spinodal decomposition in ferrite, while the neutron irradiation after thermal aging shows an exaggerated effect by further increasing the extent of FeCr separation. 
As shown in Fig. 3, to quantify the spinodal decomposition, the Cr-Fe concentration distributions are plotted by using the function of “Create Frequency Distribution Analysis” in IVAS software. The atoms in solute clusters were excluded from the analysis, and the bin size of ions is 100 . For comparison, theoretical normal distributions of $\mathrm{Cr}$ and Fe were also calculated based on the measured average concentrations in the examined APT specimens. Apparently, the as-cast ferrite has nearly perfect normal distributions of $\mathrm{Cr}$ and $\mathrm{Fe}$, and the profile peaks are located at 25.24 and 65.88 at.\%, respectively. This is consistent with the $\mathrm{Cr}$ atom map shown in Fig. 2 that there is no spinodal decomposition occurring in the as-cast ferrite. Coincidently, the 10,000 hours annealing at $400^{\circ} \mathrm{C}$ produced a nearly identical Cr-Fe concentration profile with that of 0.08 dpa neutron irradiation at $315^{\circ} \mathrm{C}$. Both the $\mathrm{Cr}$ and $\mathrm{Fe}$ peaks become broader after thermal aging or neutron irradiation. The Cr peak broadening to a lower concentration (<25.24 at.\%) corresponds to the increased volume of Cr depleted zone, and broadening to a higher concentration ( $>25.24 \%$ ) indicates increased volume of Cr enriched zones. For the condition of aged and irradiated, both the Cr frequency profile peaks shift to left, while the profile is also broadening into the high concentration range. To quantify the extent of spinodal decomposition, the measured values of $\mathrm{C}_{\mathrm{sd}}$ as illustrated on Fig. 3 are 0,13.37, 13.37 and 14.97 at.\% for conditions of as cast, aged, irradiated, and aged plus irradiated, respectively. For the Fe atoms, the concentration frequency profiles show a similar trend by deviating from a nominal distribution upon thermal aging, irradiation or a combination of those two. Basically, our study clearly demonstrates that low dose neutron irradiation could induce a spinodal decomposition of delta ferrite in a similar fashion to that induced by thermal aging. Furthermore, the low-dose irradiation on thermal aged ferrite could promote further spinodal decomposition and lead to a higher extent of un-mixing of $\mathrm{Cr}$ and $\mathrm{Fe}$ atoms in the ferrite.

\subsection{G-phase precipitations}

Figure 4 is the isosurface plots of the Mn-Ni-Si solute clusters. Overall, the G-phase precipitates behave in a similar way with that of spinodal decomposition upon thermal aging and neutron irradiation. As shown in Fig. 4, both thermal aging and irradiation individually induce solute clustering. Typically, for the ferrite phase in a cast stainless steel, upon low temperature thermal aging $\left(<400^{\circ} \mathrm{C}\right)$, the possible precipitates are $\mathrm{G}$, $\mathrm{R}$ and $\pi$ phases, where $\mathrm{G}$ phase is enriched with $\mathrm{Ni}, \mathrm{Si}, \mathrm{Mn} / \mathrm{Mo}$, R phase is a Mo-rich intermetallic phase, and $\pi$ phase is nitride. Base on the chemical composition found in this study, it is highly suspected that those Mn-Ni-Si clusters are 
G-phase precipitates. Nevertheless, further TEM diffraction study for crystallography characterization is needed for fully determining the precipitates' nature. To quantitatively identify the solute clusters, the maximum separation method (MSM) is employed and it has been commonly used by other researchers for identifying nano-sized solute precipitates [19-21]. To create a cluster analysis using IVAS software, parameters of "ions” (element), “orders" (ions), "erosion distance $d_{e}$ ”, “ $d_{\max }(\mathrm{nm})$ ", " $N_{\min }$ " and "envelop parameter $L(\mathrm{~nm})$ " have to be specified. Base on our preliminary analysis, Mn ions show the best distribution contrast between matrix and clustered regions. Thererfore, for this cluster analysis, Mn is chosen as the ion for determining the solute cluster regions. To select the desired orders (ions), the Mn-Mn nearest neighbor distributions for orders of one to ten are plotted in Fig. 5 (a), and it is found that $4^{\text {th }}$ order of nearest neighbor starts to shows a clear separation of ions in between matrix and cluster regions, with the left peak representing the ions in cluster regions and the right peak representing the ions in a more diluted matrix regions. The $4^{\text {th }}$ order nearest neighbor distribution is then fitted using two Gaussian distributions, as shown in Fig. 5 (b). The value of $d_{\max }$ is determined as the distance between zero and the crossover of two fitted Gaussian distributions. The value of $d_{e}$ is the distance between the peak of left Gaussian distribution and the crossover of two Gaussian distributions. As suggested by Y. Chen et al., envelope parameter $L$ equals to $d_{\max }$ [19]. To determine parameter $N_{\min }$, the minimum of ions in a cluster for being counted in the analysis, the curve of identified cluster number vs. $N_{\min }$ is plotted in Fig. 5 (c), for this case, a reasonable choice for $N_{\min }$ is 20, and it eliminates clusters containing few atoms while gives a stable number of clusters, as increasing $N_{\min }$ does not significantly change the number of clusters. Table 3 lists the parameters selected for all the three analysis.

The radial chemical concentration profiles in the solute clusters are plotted in Fig. 6. The analyses are based on an average over all the identified precipitates for each condition. The spatial statistics are based on solute ions, and the ions are transformed to coordinates relative to each precipitate. The precipitate model in this analysis uses the maximum distance (Maximum Delta) of constituent ion positions along each of the precipitate axes instead of radius of gyration $\left(\mathrm{R}_{\mathrm{g}}\right)$, and the distance is normalized to Maximum Delta. The precipitates are enriched in $\mathrm{Ni}, \mathrm{Mn}$ and $\mathrm{Si}$ for both the thermally aged and irradiated ferrites, which is a representative elemental composition of a G-phase precipitate. However, a significant difference between the aged and irradiated ferrite is that the precipitates in the irradiated ferrites with or without thermal aging 
both contain a significant amount of phosphorus and molybdenum. Particularly, the precipitates in the irradiated ferrite without prior thermal aging have a much higher phosphorus concentration than that from other two conditions.

Figure 7 shows comparisons in the maximum size, mean size and volumetric number density of G-phase precipitates in the ferrites at three conditions. Clearly, the combination of thermal aging and low dose neutron irradiation introduces a nearly doubled number density along with the largest maximum and mean sizes of precipitates among those three conditions. Overall, this low dose neutron irradiation does have a significant impact on the total volumetric fraction of the Gphase precipitates and their chemical compositions.

\subsection{Discussions}

Ideally, to study the synergistic effect of thermal aging and neutron irradiation on the ferrite in a duplex stainless steel, the material should subjected to the actual working temperature and dose rate as anticipated in a LWR. Thus the thermal aging and irradiation would affect the microstructure simultaneously and interactively. Unfortunately, it is practically not possible to pursue a real-time aging experiment for 60 years or beyond. As an alternative, post-accelerated aging neutron irradiation at a low temperature $\left(315^{\circ} \mathrm{C}\right)$ and a very low dose rate (in the order of $10^{-8} \mathrm{dpa} / \mathrm{s}$ ) would provide scientific insight for understanding a combined effect of thermal aging and neutron irradiation. In many cases, the thermal aging has to be accelerated at a higher temperature to complete the experiment in a reasonable time frame. It has been reported that the activation of spinodal decomposition in a Fe-Cr system has a wide range of 164 to $324 \mathrm{~kJ} / \mathrm{mole}$ [11, 22], and an optimal accelerated aging temperature is yet unanimously agreed upon. Although the thermal aging of $400^{\circ} \mathrm{C}$ used in this paper might not be the prototypical reactor operation temperature, when recognizing the complexities leading to significant uncertainties in determining an optimal temperature, $400^{\circ} \mathrm{C}$ is believed to be representative of very slow aging mechanisms [23]. By considering the low end of activation energy $164 \mathrm{~kJ} / \mathrm{mole}, 10,000$ hours aging at $400^{\circ} \mathrm{C}$ will correspond to 49 years of service at $323^{\circ} \mathrm{C}$ in a LWR.

Apparently, both the neutron irradiation and thermal aging can induce solute clustering in the ferrite, however, the chemical composition and average size of the G-phase precipitates are 
different. Figure 8 shows that the irradiated condition significantly promotes the contents of $\mathrm{Si}$, $\mathrm{Ni}, \mathrm{Mn}, \mathrm{P}$ and $\mathrm{Mo}$ in the precipitates as compared with the thermally aged condition. The data for plots in Fig. 8 is listed in Table 4, and the data wad derived by summing all the ions in identified solute clusters for each alloying element. Thermal aging enhances the diffusion of mainly oversized atoms, while the irradiation would enhance the diffusion of self-interstitials and vacancies of both the undersized and oversized atoms through mixed-dumbbell and vacancy mechanisms. The order of the atomic radii is $\mathrm{Mo}>\mathrm{Cr}>\mathrm{Mn}>\mathrm{Fe}>\mathrm{Ni}>\mathrm{Si}>\mathrm{P}$. Irradiation induces a significant concentration of phosphorus interstitials, which further segregate into solute clusters. For the aged and irradiated condition, further increases of $\mathrm{Ni}, \mathrm{Mn}$ and $\mathrm{Si}$ in precipitates after neutron irradiation are consistent with the observation in the irradiated slag weld overlay cladding of reactor pressure vessels as compared with thermal aging [16]. However, the relative low concentration of phosphorus in the precipitates as compared with that in the irradiated only condition should be due to the possible depletion of phosphorus atoms from the matrix while the significantly increasing solute cluster size and total volume. Figure 9 shows the correlations between the chemical concentrations of $\mathrm{P}$ and $\mathrm{Mo}$ and the number of solute ions in each corresponding cluster. Clearly, all the precipitates in the aged and irradiated ferrite contain phosphorus and molybdenum while the small clusters tend to have a lower concentration of phosphorus. This indirectly demonstrates that the depletion of phosphorus atoms from matrix as the newly nucleated clusters tend to have a much less phosphorus conconcentration.

The combined effect from thermal aging and neutron irradiation on the ferrite phase degradation is demonstrated on both the spinodal decomposition and G-phase precipitation in this study. As reviewed by Wilkes [24], it was experimentally and theoretically shown that irradiation-induced disordering competes with the process of thermal ordering. The resulting phase structure is strongly dependent on the defect production rate and the irradiation temperature, which determine the concentration of defects and their mobility. Either the radiation accelerates the approach to thermal equilibrium, or radiation-induced non-equilibrium phase precipitation happens. The underlying mechanisms of microstructural evolution can be further complicated by $\mathrm{Mn}, \mathrm{Mo}$, Si and other minor alloying elements. One recent study shows that $6.4 \mathrm{MeV} \mathrm{Fe}^{3+}$ ion irradiation at $300^{\circ} \mathrm{C}$ can suppress spinodal decomposition, by decreasing the fluctuation of $\mathrm{Cr}$ concentration in the Cr-rich $\alpha$ ' phase [18]. However, Miller et al [17] studied the effect of 
neutron irradiation on spinodal decomposition of a Fe-Cr model alloy, and it was found that the spinodal decomposition in a Fe-32\% Cr alloy was significantly enhanced by neutron irradiation after $0.03 \mathrm{dpa}$ at $290^{\circ} \mathrm{C}$. This controversy regarding irradiation effect on the spinodal decomposition of aged ferrite can be attributed to the difference in incident particles, dose rate,

temperature and the material itself. The dose rate in this study $\left(10^{-9} \mathrm{dpa} / \mathrm{s}\right)$ is at the same order of that used in Miller's study, therefore, it is not surprising that both studies show an enhancement of spinodal decomposition from neutron irradiation.

\section{Summary}

Microstructural changes in the ferrite of thermally aged, neutron irradiated and thermal aged plus neutron irradiated cast stainless steels were investigated using APT. It was found that low dose rate neutron irradiation could effectively induce spinodal decomposition in the ferrite of as-cast CASS, while the neutron irradiation of aged CASS would further enhance the spinodal decomposition. The neutron irradiation would not only dramatically increase the size of G-phase precipitates, but also increases the concentration of Mn, Ni, Si and Mo in the G phase precipitate. This study proves that the effects of neutron irradiation on the ferrite degradation are highly depending on the radiation dose rate at a LWR relevant temperature, and it is suspected that there could be an accelerated effect between thermal aging and neutron irradiation on the duplex stainless steel serving in a LWR reactor.

\section{Acknowledgement}

The authors would like to thank the program manager Dr. Rao at the Nuclear Regulatory Commission for his strong support. This research was sponsored by the U. S. NRC under the Job Code V6454 as subcontract from Argonne National Laboratory and direct fund number NRCHQ-14-G-0014. The APT experiments were conducted utilizing the CAES facility through the ATR-National Scientific User Facility Rapid Turnaround Program.

\section{Reference}


[1] J.M. Sassen, M.G. Hetherington, T.J. Godfrey, G.D.W. Smith, P.H. Pumphrey, K.N. Akhurst, Properties of Stainless Steels in Elevated Temperature Service. Presented at the Winter Annual Meeting of the American Society of Mechanical Engineers, Boston, MA, USA, 1987.

[2] P.H. Pumphrey, K.N. Akhurst, Mat. Sic. and Tech., 6 (1990) p. 211-219.

[3] O.K. Chopra, A. Sather, NUREG/CR5385 U.S. NRC Office of Nuclear Regulatory Research, 1990.

[4] H.M. Chung, Int. J. Pres. Ves. \& Piping, 50 (1992) 179-213.

[5] H.M. Chung, O.K. Chopra, 3rd Int. Conf. on Environ. Degrad. Mater. Nucl. Power Sys. - Water

React., Traverse City, MI, United States, Aug 30-Sep 3, 1987.

[6] O.K. Chopra, A.S. Rao, J. Nucl. Mat., 412 (2011) 195-208.

[7] X.T. Wang, S.L. Li, S.X. Li, Y.L. Wang, F. Xue, G.G. Shu,Mater. Res. Soc. Symp. Proc. , 1215, (2010)

[8] M.D. Mathew, L.M. Lietzan, K.L. Murty, V.N. Shah, Mat. Sic. and Eng. , A269 (1999) 186-196.

[9] T. Takeuchi, J. Kameda, Y. Nagai, T. Toyama, Y. Nishiyama, K. Onizawa, J. Nucl. Mat., 415 (2011) 198-204.

[10] J. Zhou, J. Odqvist, M. Thuvander, S. Hertzman, P. HedstrÖm, Acta Mat., 60 (2012) 5818-5827.

[11] C. Pareige, S. Novy, S. Saillet, P. Pareige, J. Nucl. Mat., 411 (2011) 90-96.

[12] T. Takeuchi, J. Kameda, Y. Nagai, T. Toyama, Y. Matsukawa, Y. Nishiyama, K. Onizawa, J. Nucl. Mat., 425 (2012) 60-64.

[13] T. Lucas, R.G. Ballinger, H. Hanninen, T. Saukkonen, 15th Int. Conf. on Environ. Degrad. Mater.

Nucl. Power Sys. - Water React., Colorado Spring, CO, United State, Aug. 7 - 11, 2011.

[14] Materials Reliability Program: thermal aging and neutron embrittlement assessment of cast ausenitic stainless steels and stainless steel welds in PRW internals (MRP-276) EPRI, Palo Alto, CA: 2010. 1020959,

[15] Materials Reliability Program: PWR internals materials aging degradation mechanism screening and threshold values (MRP-175) EPRI, Palo Alto, CA: 2005. 1012081,

[16] T. Takeuchi, Y. Kakubo, Y. Matsukawa, Y. Nozawa, Y. Nagai, Y. Nishiyama, J. Katsuyama, K. Onizawa, M. Suzuki, J. Nucl. Mat., 443 (2013) 266-273.

[17] M.K. Miller, R.E. Stoller, K.F. Russell, J. Nucl. Mat., 230 (1996) 219-225.

[18] K. Fujii, K. Fukuya, J. Nucl. Mat., 440 (2013) 612-616.

[19] Y. Chen, P. Chou, E.A. Marquis, J. Nucl. Mat., 451 (2014) 130-136.

[20] C. Williams, D. Haley, E.A. Marquis, G.D.W. Smith, M.P. Moody, Ultramicroscopy, 132 (2013) 271-278.

[21] M.K. Miller, E.A. Kenik, K.F. Russell, L. Heatherly, D.T. Hoelzer, P.J. Maziasz, Mat. Sic. and Eng. A, 353 140-145.

[22] F. Danoix, P. Auger, Mater. Charct., 177 (2000) 177-201.

[23] T.S. Byun, J.T. Busby, ORNL/LTR-2012/440 2012.

[24] P. Wikes, J. Nucl. Mat., 1979 (1979) 166-175. 
Table 1 Chemical composition (wt\%) of the cast stainless steel CF3.

\begin{tabular}{llllllllll}
\hline $\mathrm{Ni}$ & $\mathrm{Si}$ & $\mathrm{P}$ & $\mathrm{S}$ & $\mathrm{Mn}$ & $\mathrm{C}$ & $\mathrm{N}$ & $\mathrm{Cr}$ & $\mathrm{Mo}$ & $\mathrm{Fe}$ \\
\hline 8.59 & 1.13 & 0.015 & 0.005 & 0.63 & 0.023 & 0.028 & 20.18 & 0.34 & Bal. \\
\hline
\end{tabular}


Table 2 APT measured chemical composition (wt.\%) of the ferrite at difference conditions.

\begin{tabular}{|l|l|l|l|l|l|l|l|l|l|}
\hline Condition & $\mathrm{Ni}$ & $\mathrm{Si}$ & $\mathrm{P}$ & $\mathrm{S}$ & $\mathrm{Mn}$ & $\mathrm{C}$ & $\mathrm{Cr}$ & $\mathrm{Mo}$ & $\mathrm{Fe}$ \\
\hline As cast & 5.61 & 1.36 & 0.028 & 0.0009 & 0.57 & 0.006 & 24.45 & 0.618 & 67.34 \\
\hline Aged & 5.71 & 1.37 & 0.026 & 0.0015 & 0.56 & 0.011 & 23.61 & 0.658 & 68.05 \\
\hline Irradiated & 5.30 & 1.39 & 0.042 & 0.0012 & 0.54 & 0.009 & 24.11 & 0.657 & 67.95 \\
\hline $\begin{array}{l}\text { Aged } \\
\text { \&Irradiated }\end{array}$ & 5.87 & 1.25 & 0.028 & 0.0015 & 0.55 & 0.013 & 23.06 & 0.664 & 68.19 \\
\hline $\begin{array}{l}\text { Standard } \\
\text { deviation }\end{array}$ & 0.05 & 0.01 & 0.001 & 0.0003 & 0.002 & 0.0006 & 0.13 & 0.005 & 0.08 \\
\hline
\end{tabular}


Table 3 Parameters for the solute cluster analysis.

\begin{tabular}{|l|l|l|l|l|l|}
\hline Conditions & Ions & Orders & $d_{\max }=L(\mathrm{~nm})$ & $d_{e}(\mathrm{~nm})$ & $N_{\min }$ \\
\hline Aged & $\mathrm{Mn}$ & 10 & 1.22 & 0.3 & 15 \\
\hline Irradiated & $\mathrm{Mn}$ & 4 & 0.8 & 0.2 & 11 \\
\hline $\begin{array}{l}\text { Aged and } \\
\text { Irradiated }\end{array}$ & $\mathrm{Mn}$ & 4 & 0.9 & 0.3 & 20 \\
\hline
\end{tabular}


Table 4 Chemical concentration (at.\%) data for the plots in Fig 8.

\begin{tabular}{|l|l|l|l|l|l|l|l|}
\hline Condition & Mo & P & Mn & Ni & Fe & Cr & Si \\
\hline Aged & 0.67 & 0.18 & 3.09 & 13.72 & 51.30 & 24.50 & 6.22 \\
\hline Irradiated & 1.55 & 3.03 & 5.60 & 26.62 & 31.76 & 19.11 & 11.35 \\
\hline Aged and Irradiated & 1.33 & 0.90 & 7.98 & 30.10 & 29.65 & 15.75 & 13.42 \\
\hline
\end{tabular}




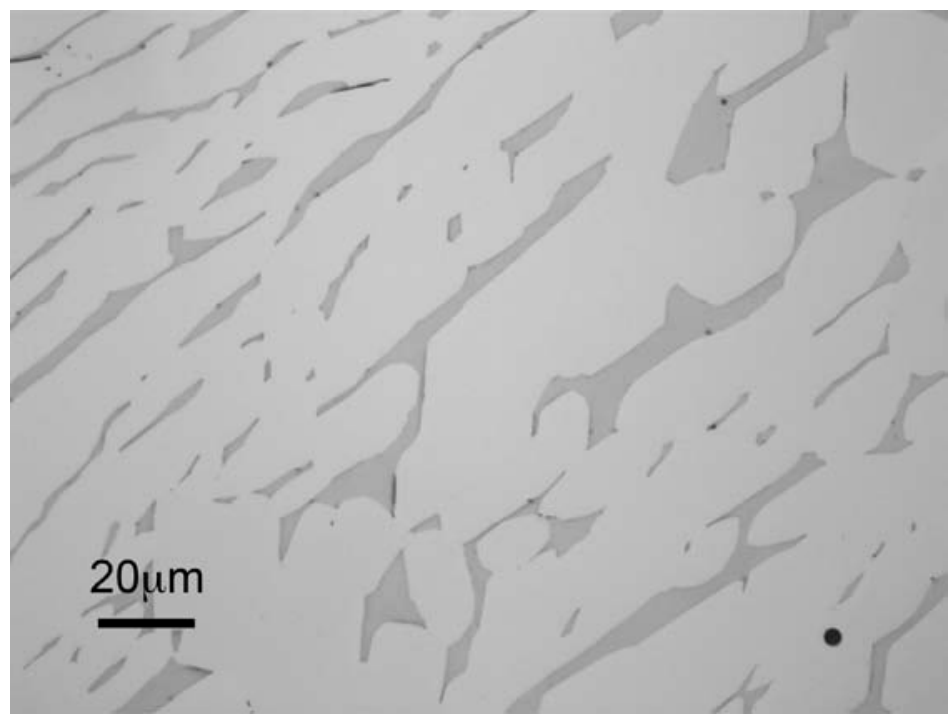

Fig 1. Optical image of the as-cast CF-3 stainless steel etched using a Viella's agent for 30 seconds. The dark areas represent ferrite phase, and the grey areas are the austenite matrix. 


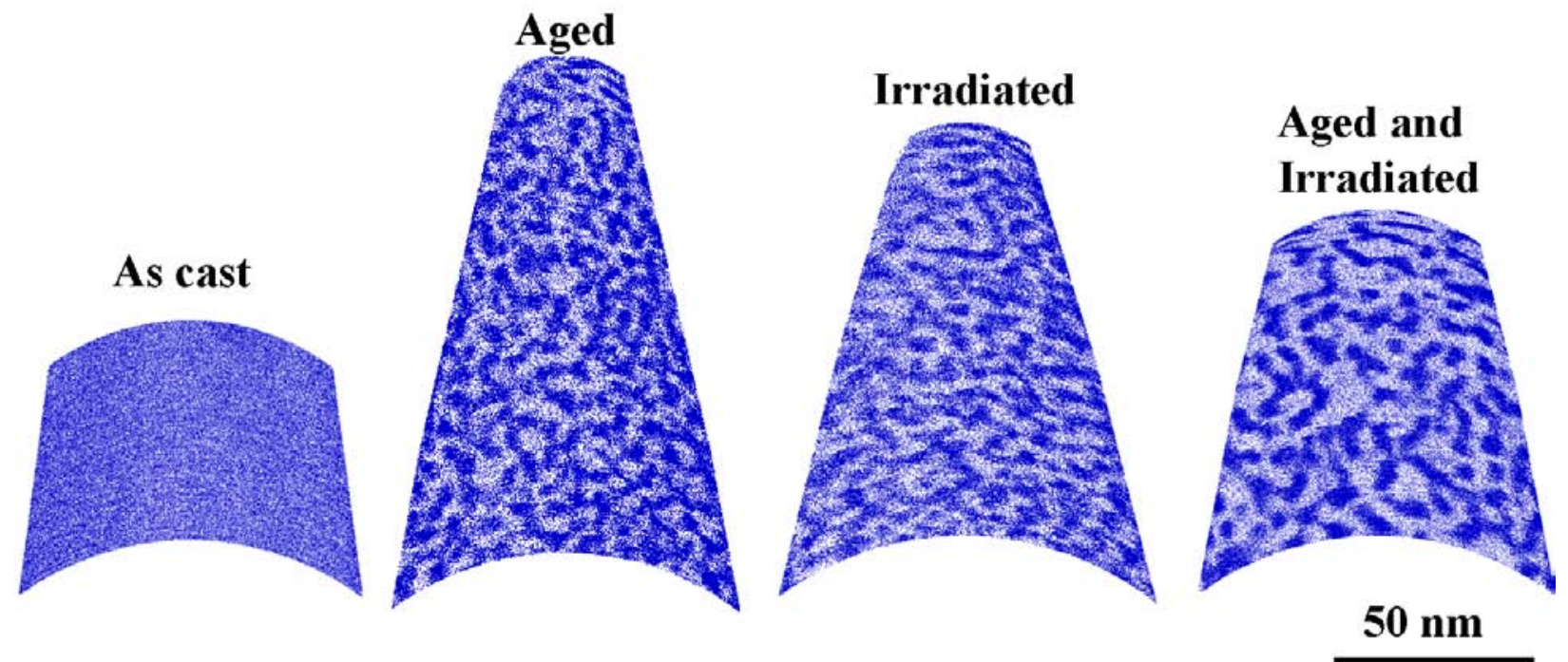

Fig. 2. Spinodal decomposition in ferrite of cast stainless steels, where the blue color represents $\mathrm{Cr}$ atoms. 


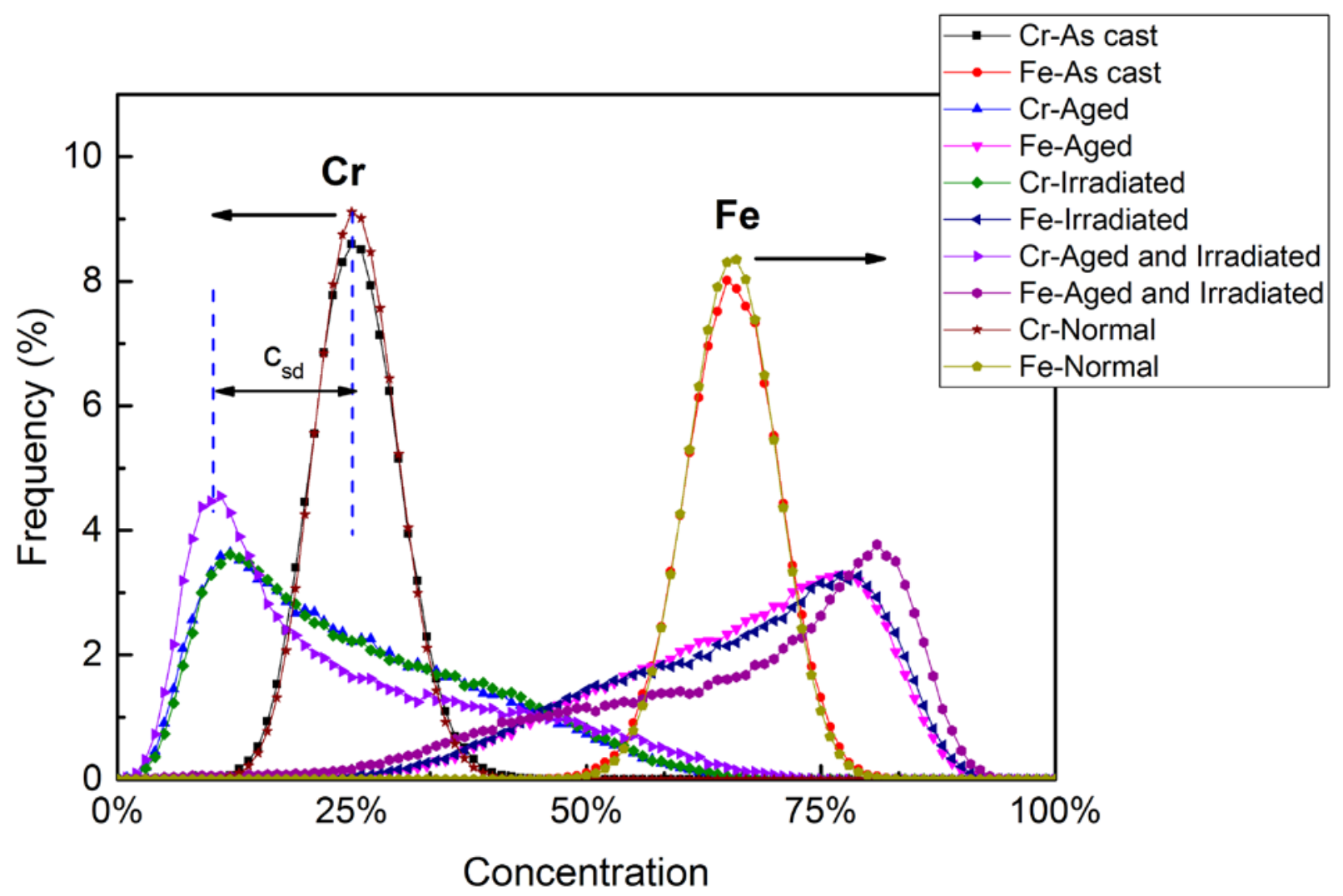

Fig. 3. Fe-Cr elemental frequency distributions in ferrites upon different conditions. 


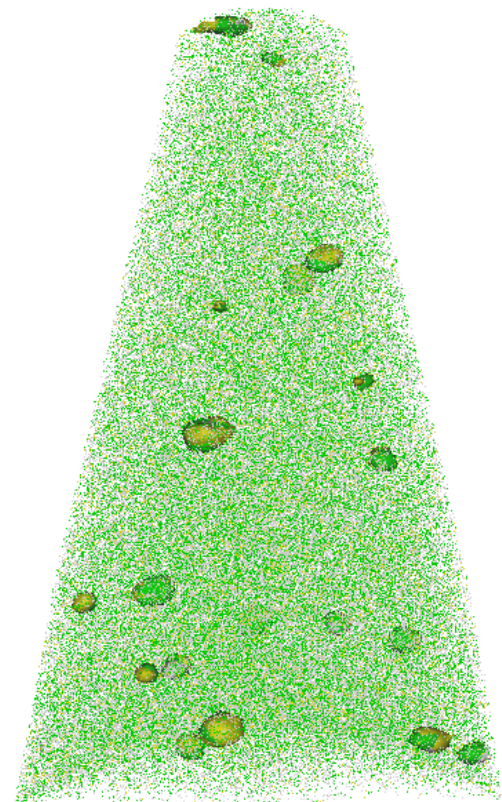

Aged

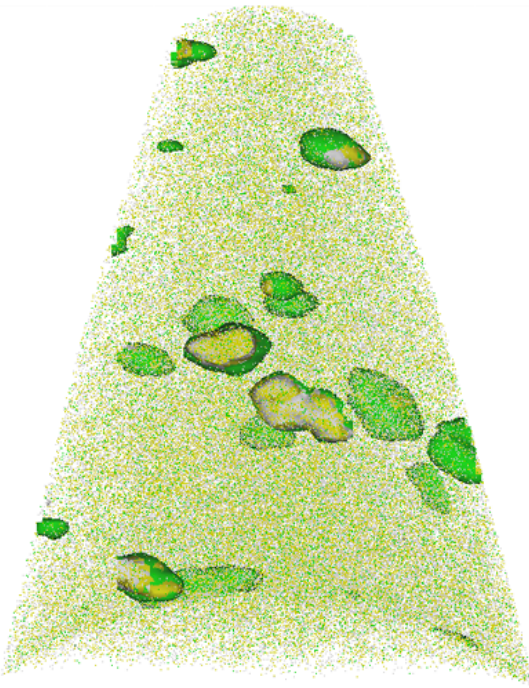

Irradiated
$\mathrm{Mn} \square \mathrm{Ni} \square \mathrm{Si}$

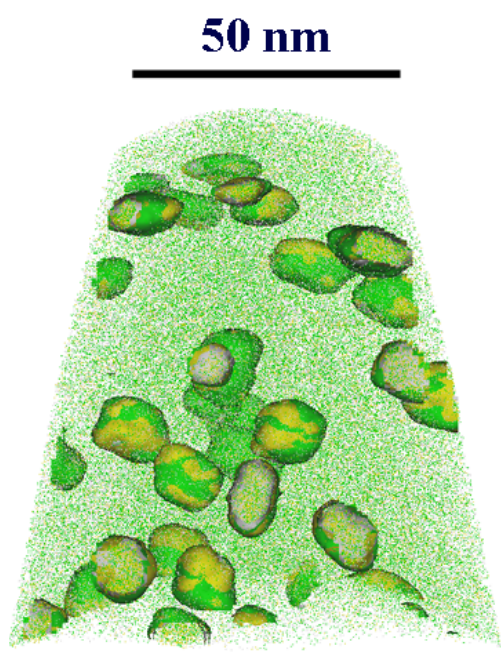

Aged and Irradiated

Fig. 4. G-phase precipitates in aged, irradiated, and aged-irradiated ferrites . The images are sized to have an identical scale, and the isovalue thresholds of Mn, Ni and Si are 2, 10 and 6 $\%$, respectively. 
(a)

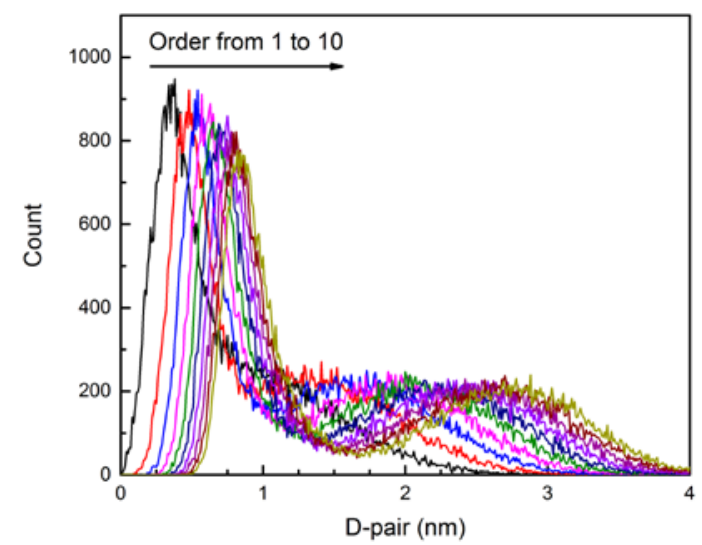

(b)

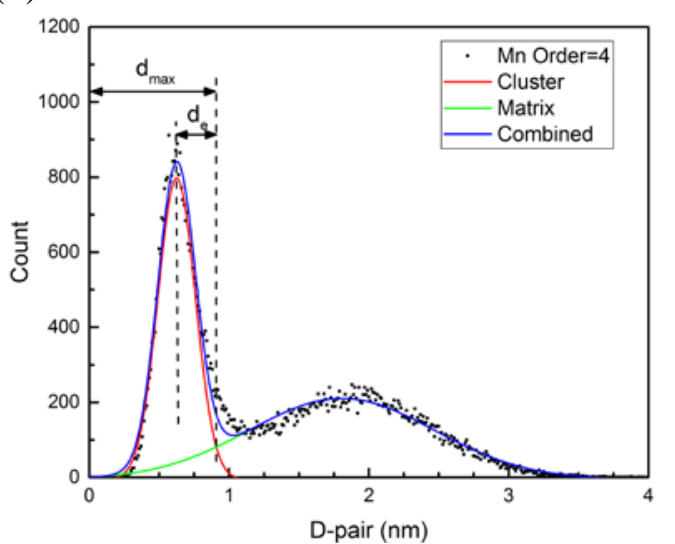

(c)

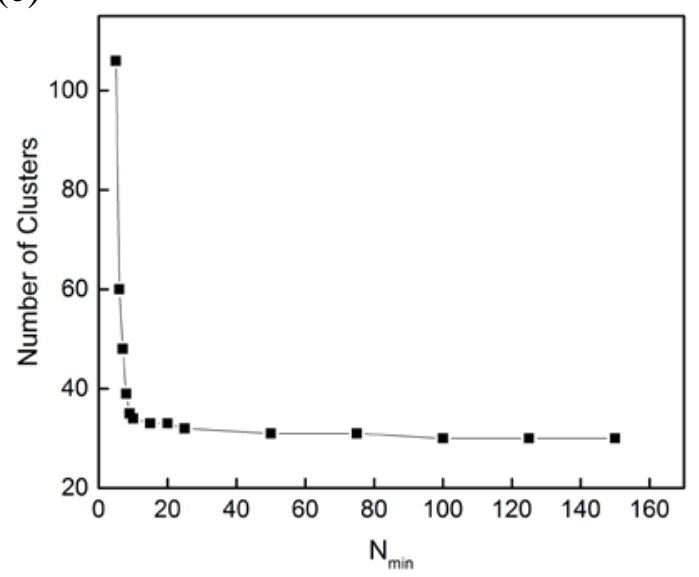

Fig. 5. Cluster analysis parameters selection using the aged and irradiated ferrite as an example:

(a) Mn-Mn nearest neighbor distributions for orders from 1 to 10, (b) Gaussian peak deconvolution for the $4^{\text {th }}$ order nearest neighbor distribution and determination of $d_{m a x}$ and $d_{e}$, and (c) selection of the $N_{\min }$. 

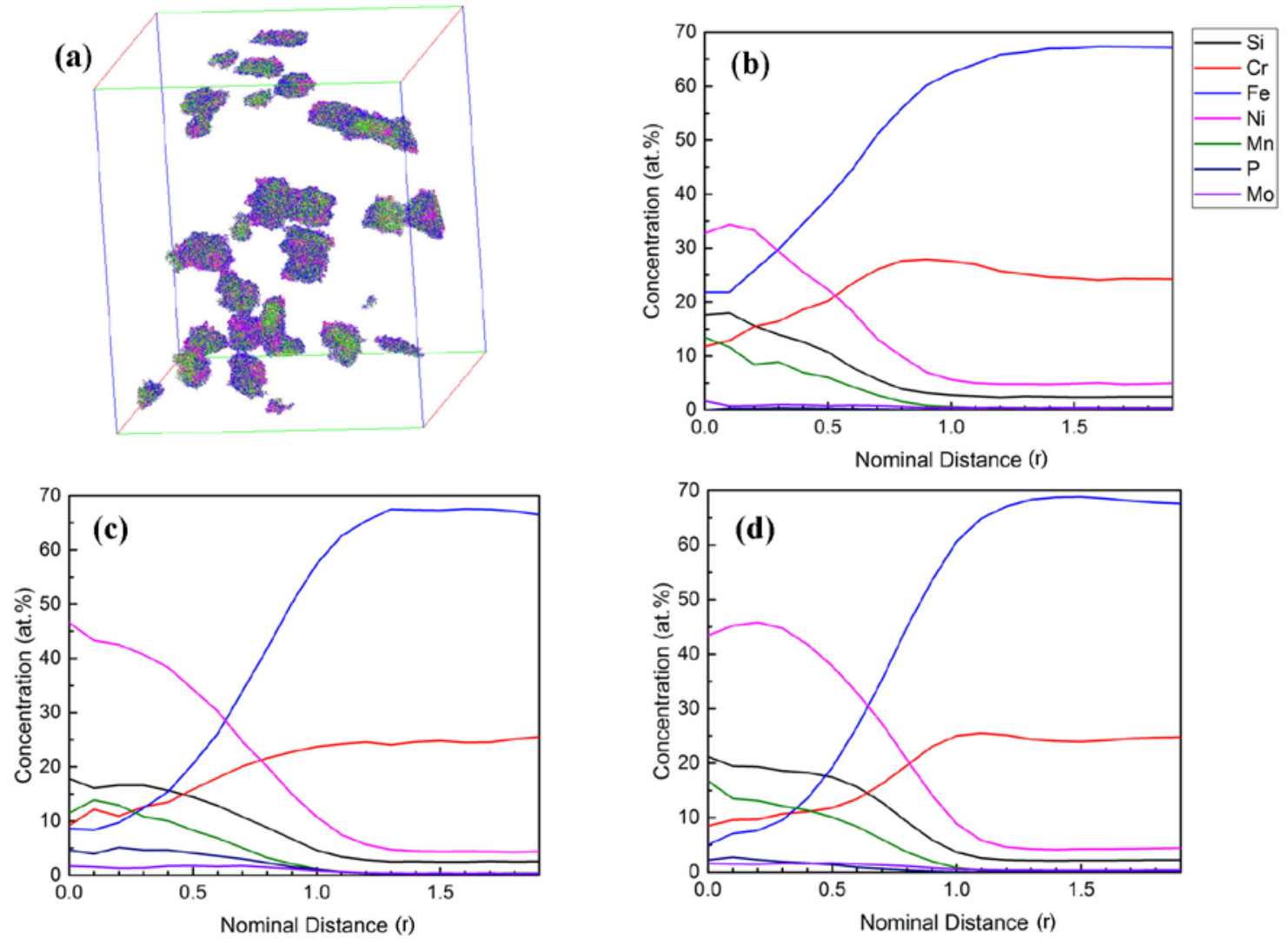

Fig. 6. (a) Example of the identified solute clusters, and radial elemental distribution of G-phase precipitates in (b) aged, (c) irradiated, and (d) aged \& irradiated ferrites. 


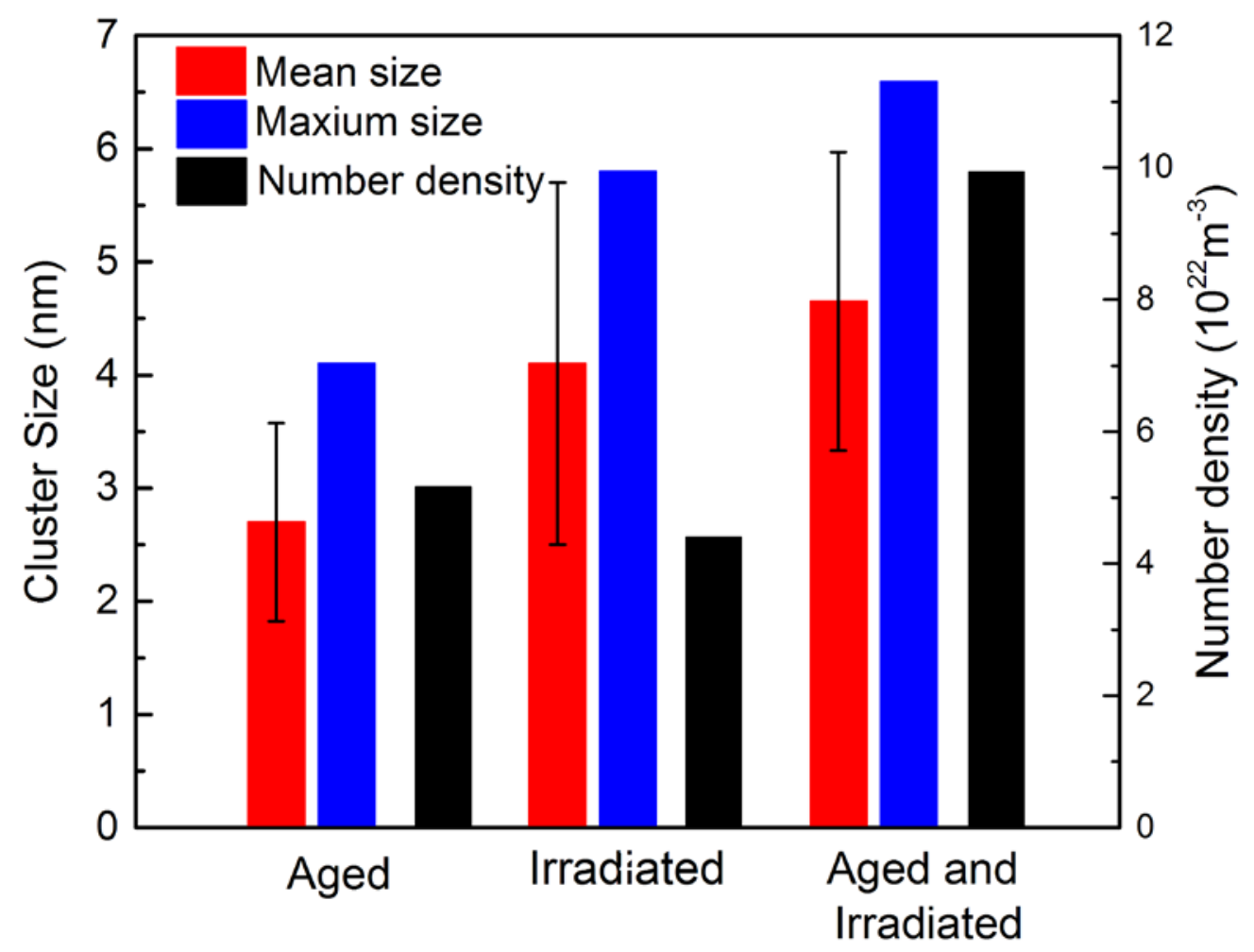

Fig. 7. Maximum size, mean size and volumetric number density of G-phase precipitates. 


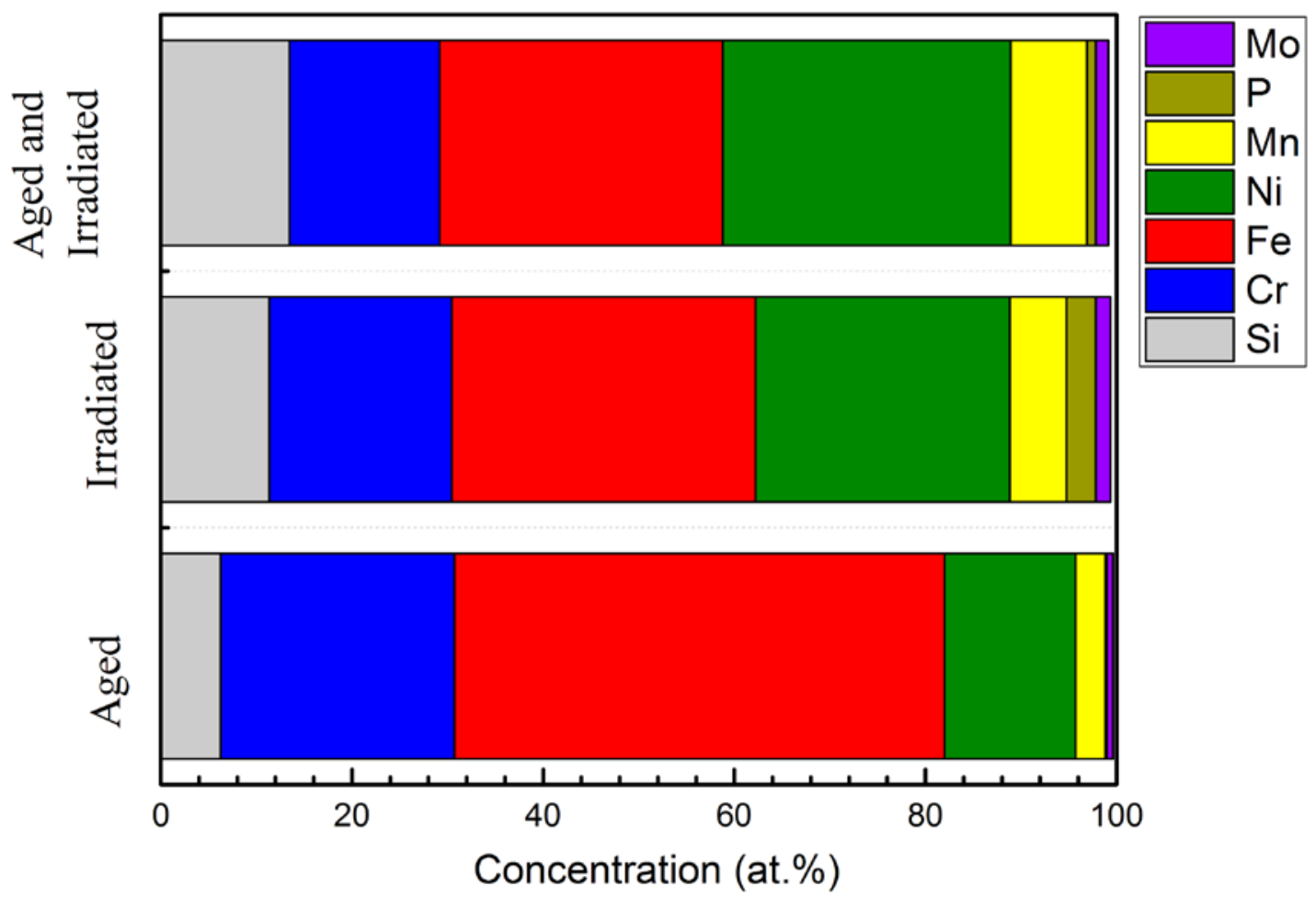

Fig. 8. Chemical composition of the G-phase precipitates in ferrites. 
(a)

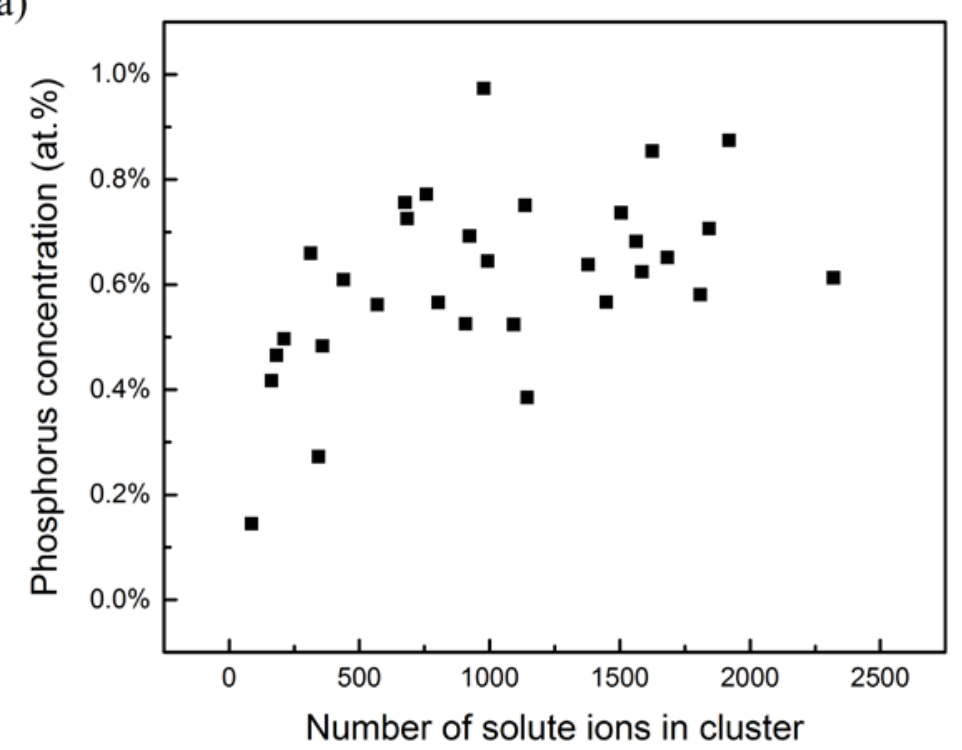

(b)

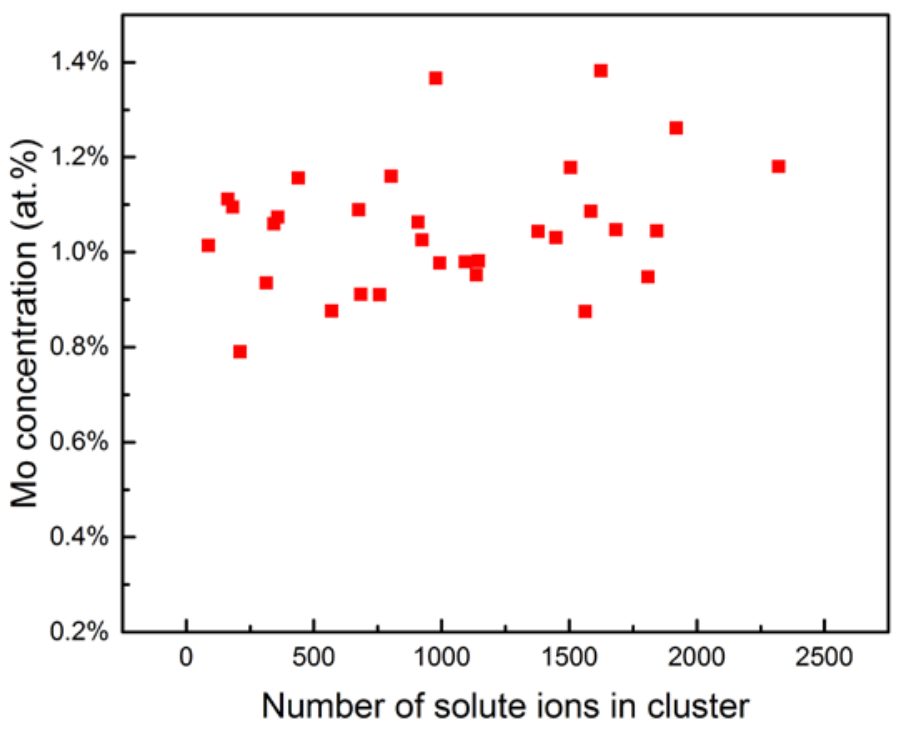

Fig. 9. Correlation between elemental concentration and the number of solute ions in cluster for (a) phosphorus and (b) molybdenum. 